\title{
Eliot Slater's myth of the non-existence of hysteria
}

\author{
Jon Stone ${ }^{1} \quad$ Charles Warlow $^{2} \quad$ Alan Carson $^{3} \quad$ Michael Sharpe $^{4}$
}

J R Soc Med 2005;98:547-548

Mrs $\mathrm{T}$ presents to the general neurology clinic on a busy Tuesday morning. She has a 1-year history of right-sided weakness, fatigue, back pain and sleep disturbance and is in a wheelchair. She has a large file full of other symptoms for which no convincing disease explanation has ever been found. Examination confirms inconsistent weakness with a positive Hoover's sign and symmetrical reflexes. Investigations including MRI brain scan are normal. The diagnosis is functional weakness, which might also be called conversion disorder or psychogenic weakness. In years gone by it would have been called 'hysteria'.

Patients like Mrs T are quite common in neurological practice. A recent study from our group found that patients with weakness unexplained by disease may be as common as those with multiple sclerosis (MS). Furthermore, they are deserving patients with chronic disability and distress. ${ }^{1}$ But, hang on a minute, do they really exist at all? Was there not a classic paper by Slater that proved that they all received a neurological diagnosis in the end?

Eliot Slater (1904-1983) was founder of the Psychiatric Genetics Unit at the Institute of Psychiatry in 1959 and also held a post at the Institute of Neurology (1946-1959). The paper in question, 'Diagnosis of "Hysteria", , was published in the $B M J$ in $1965 .^{2}$ It was a lecture transcript which described a follow up study of 112 patients with a diagnosis of 'hysteria' seen at the Institute of Neurology an average of nine years earlier. ${ }^{3}$ Despite its classic status, a cursory read reveals major flaws in its design and reporting. Slater conflates together patients who were truly misdiagnosed (e.g. someone with 'hysterical weakness' who turned out to have an 'atypical myopathy') with those who merely had 'co-morbidity' (e.g. a patient with MS and 'hysterical elaboration' who at follow up had only MS). He did not report clearly what symptoms the patients had, or on what basis they were misdiagnosed. Even some of the apparent misdiagnoses seem to be of dubious relevance (for example, 'cortical atrophy'). Yet, this was his clear and robust conclusion:

${ }^{1}$ Consultant Neurologist, ${ }^{2}$ Professor of Medical Neurology, ${ }^{3}$ Consultant Neuropsychiatrist, ${ }^{4}$ Professor of Psychological Medicine and Symptoms Research, School of Molecular and Clinical Medicine, University of Edinburgh, Western General Hospital, Crewe Road, Edinburgh EH4 2XU, Scotland, UK

Correspondence to: Dr Stone

E-mail: Jon.Stone@ed.ac.uk
"No evidence has yet been offered that the patients diagnosed as suffering from "hysteria" are in medically significant terms anything more than a random selection... The only thing that hysterical patients can be shown to have in common is that they are all patients. The malady of the wandering womb began as a myth, and a myth it yet survives. But like all unwarranted beliefs which still attract credence, it is dangerous. The diagnosis of "hysteria" is a disguise for ignorance and a fertile source of clinical error. It is in fact not only a delusion but a snare.'

So why does this paper matter? It matters because of the paper's huge impact on medical science and practice. Despite a fierce rebuke from the neurologist Sir Francis Walshe later that year in the $B M J,{ }^{4}$ his conclusion that a diagnosis of hysteria is 'not only a delusion but a snare' has resonated down the decades. For the next 30 years, Slater's study turns up again and again in the literature as solid 'evidence' that patients with complaints regarded as 'nonorganic' or evidence of 'conversion disorder' are just misdiagnosed cases of disease which will eventually emerge.

Why did it become a classic? Perhaps because it was a blessing for psychiatrists. The typical patient with conversion symptoms is rarely enthusiastic about seeing a psychiatrist. Slater's study provided a wonderful excuse to send the patient back to the neurologist with an opinion that there was 'no psychiatric disorder' and that the symptoms would probably turn out to be due to a disease. Neurologists, for their part, appeared to carry on diagnosing 'hysteria' but remained uninterested in the topic. Perhaps it became a classic because of the memorable eloquence of the conclusion. Whatever the reason, it was not the quality of the science.

The truth is that reported misdiagnosis rates for symptoms like these were around $15 \%$ before his study and have averaged only $4 \%$ in studies of patients since 1970 , a rate no worse than for any other neurological or psychiatric condition. ${ }^{5}$ Slater made a valid point about the overly broad use of the word 'hysteria' at the time, but he also denied the existence of symptoms such as functional weakness and non-epileptic attacks. In doing so, he unwittingly stunted research and impeded the clinical care of these patients, a situation from which we are only now recovering. Perhaps above all it should 
remind us how easily we can be led to believe what is convenient and eloquently expressed, rather than what is scientifically true.

\section{REFERENCES}

1 Stone J, Sharpe M, Deary I, Warlow C. Functional paresis: paradoxes in illness beliefs and disability in 107 subjects [Abstract]. J Neurol Neurosurg Psychiatry 2003;75:518
2 Slater ET. Diagnosis of 'hysteria'. BMJ 1965;i:1395-9

3 Slater ET, Glithero E. A follow-up of patients diagnosed as suffering from "hysteria". J Psychosom Res 1965;9:9-13

4 Walshe F. Diagnosis of hysteria. BMJ 1965;ii:1451-4

5 Stone J, Smyth R, Carson A, et al. Systematic review of misdiagnosis of conversion symptoms and "hysteria". doi:10.1136/bmj. 38628.466898.55 (published 13 October 2005) [http://bmj. bmjjournals.com/cgi/rapidpdf/bmj.38628.466898.55v1] accessed 18 October 2005

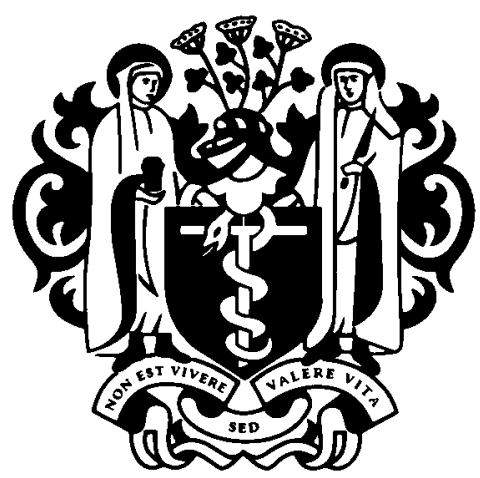

The Coat of Arms of The Royal Society of Medicine was designed by Martin Travers in 1927 and employs several significant medical and surgical references. The two supporting figures on either side are Saints Cosmas and Damian, considered since the 4th century to protect against sickness. The divisions of the shield into green and red represent physicians and surgeons, and thus the saint on the left holds an apothecary jar, while the saint on the right holds a scalpel. The legendary Greek god Asklepios, also associated with healing, is usually identified by a caduceus or staff entwined with a snake, and this too is portrayed against the shield.

Above is a flowering plant, which has been referred to as the herb 'all-heal'. This term has been used in the past for a variety of plants. The arrangement of the flowering head very much resembles an Umbellifer. This is a notoriously difficult group for anyone other than an expert botanist to identify. Some members of this group, such as hemlock, are poisonous! But among the Umbellifers, in view of the whitish flowers and leaf shape, it is possible that this is sanicle. This plant has been used from earliest times for healing. Early herbalists recommended its use for such ailments as sore throats and mouth ulcers. In the Middle Ages, it was commonly believed that 'he who keeps sanicle has no business with a doctor'.

The motto on the Coat of Arms is from Martial (Epigrams), 'Non est vivere sed valere vita', or, as the recent History of The Royal Society of Medicine by Penelope Hunting has it, 'it is important to enjoy good health to live fully'. 